\title{
Türk mutfak kültürünün şiire yansıması bağlamında Ravzî’nin pilav kasidesi
}

\section{Erdem SARIKAYA ${ }^{1}$}

APA: Sarıkaya, E. (2019). Türk mutfak kültürünün şiire yansıması bağlamında Ravzînin pilav kasidesi. RumeliDE Dil ve Edebiyat Araştırmaları Dergisi, (16), 319-327. DOI: $10.29000 /$ rumelide.618932

\section{$\ddot{O} \mathbf{z}$}

Türk mutfak kültürü, kadim bir geçmişe sahiptir. Orta Asya'da atlı-göçebe yaşam tarzını benimsemiş Türk boylarının kendilerine özgü bir mutfak kültürü vardır. Bu kültür, Orta Asya'dan göçleri sırasında geçtikleri coğrafyadaki diğer mutfak kabullerinden etkilenir. Selçuklu mutfağı, en eski devirlerde oluşmuş Türk mutfak kültürüyle İslamiyet’in getirdiği kabullerin bir sentezidir. Anadolu Selçuklu Devleti ve Türk beyliklerinin mutfak kültüründe sadelik esastır. Osmanlı saray mutfağı ise günümüz Türk mutfağının temelini oluşturur. Türk mutfağı; yemekleri, yemek pişirme teknikleri ve sunumla ilgili kabulleriyle sosyal hayattan beslenen şairler için ilham kaynağı olur. Örneğin eski dönemlerden itibaren Türk sofralarının vazgeçilmez yemeklerinden olan pilav, şiirde anlatı ögesi olarak kullanılır. XVI. asır şairlerinden Ravzî’nin pilav övgüsünde kaleme aldığı manzumesi bu durumun ilgi çekici örneklerindendir. Bu kaside, gelenekteki benzerlerinden konusu, üslubu, hayal dünyası ve kompozisyon bütünlüğündeki şairane tercihlerle ayrılan kısa bir övgü şiiridir. Şair, bu şiirinde uzun bir süredir yemediği, bu nedenle de kavuşma isteği ve özlem duygusu içerisinde olduğu pilav yemeğini çeşitli benzetmeler yaparak över. Bununla beraber devrin sultanı III. Murat'ın Atmeydanı'nda verdiği bir ziyafette pilav yediğini söyleyerek sultana dua eder. Pilavın mübalağalı bir üslupla ve çeşitli benzetmelerle övgüsü şiirin sonuna kadar sürer. Bu çalışmada, Ravzînin pilav övgüsünde kaleme aldığı manzumesi, Türk mutfak kültürünün şiire yansıması bağlamında şekil ve muhteva özellikleri açısından incelenecektir.

Anahtar kelimeler: Türk mutfağı, Osmanlı saray mutfağı, pilav, Ravzî, klâsik Türk edebiyatı.

\section{Ravzî's rice cassal in the context of the reflection of Turkish culinary culture on poetry}

\begin{abstract}
Turkish culinary culture has an ancient past. Turkish tribes who adopted the equestrian-nomadic lifestyle in Central Asia have their own culinary culture. This culture is influenced by other culinary assumptions in the geography they pass through during their migration from Central Asia. Seljuk cuisine is a synthesis of the Turkish cuisine culture that was formed in the oldest periods and the assumptions of Islam. Simplicity is essential in the culinary culture of Anatolian Seljuk State and Turkish principalities. Ottoman palace cuisine is the basis of today's Turkish cuisine. Turkish cuisine; food, cooking techniques and presentation of the inspiration for poets nurtured by social life. For example, rice, which is one of the indispensable dishes of Turkish tables since ancient times, is used as narrative element in poetry. One of the interesting examples of this situation is the poem of Ravzî, one of the poets of the 16th century, penned in praise of rice. In this eulogy, the subject of the tradition is a short poem of praise which is distinguished by its poetic preferences in the integrity of its style,

$1 \quad$ Dr. Öğr. Üyesi, Yozgat Bozok Üniversitesi, Fen-Edebiyat Fakültesi, Türk Dili ve Edebiyatı Bölümü (Yozgat, Türkiye), dr.erdemsarikaya@gmail.com, ORCID ID: oooo-0001-8402-5085 [Makale kayit tarihi: 27.06.2019-kabul tarihi:20.09.2019; DOI: 10.2900o/rumelide.618932]


imagination and composition. In this poem, the poet praises the rice dish, which he has not eaten for a long time and therefore has a desire to meet and longing, by making various metaphors. However, the Sultan of the period III. Murat prays to the sultan saying that he ate rice at a feast at Atmeydanı. The praise of rice with an exaggerated style and various metaphors continues until the end of the poem. In this study, the verse Ravzî wrote in praise of rice will be examined in terms of its shape and content features in the context of the reflection of Turkish cuisine to poetry.

Keywords: Turkish cuisine, Ottoman palace cuisine, rice, Ravzî, classical Turkish literature.

\section{Giriş}

Beslenme, insanoğlunun yaşamını devam ettirebilmesini sağlayan en temel ihtiyaçlarındandır. Bu ihtiyaçtan kaynağını alan beslenme kültürü, farklılık gösteren kabulleriyle toplumların yaşam üsluplarına dair ögeleri taşır.

Türk mutfak kültürünün kaynağı, tarihin en eski zamanlarına dayanır. Orta Asya'da atlı-göçebe yaşam tarzı süren Türk boylarının beslenme kültüründe, et ve mayalanmış süt ürünleri ön plandadır (Ögel, 1991: IV/ 23). Tarım ve hayvancılıkla uğraşan Türk boylarının mutfaklarında buğday ve buğday unundan yapılan yağlı hamur işleri, darıdan yapılan boza ve av hayvanları önemli bir yer işgal eder (Argıllı, 2005: 14). Koyun, keçi ve sığır eti ile tereyă̆ı, peynir, yoğurt, ayran, çökelek gibi süt ürünleri sıklıkla tüketilir (Ciğerim, 2001: 54). Mayalanmış kısrak sütünden imal edilen kımız, bu dönem Türk mutfağının en önemli içkilerindendir (Baysal, 1993: 32). Ziyafet sofralarının temel yemeklerinden bir tanesi haşlanmış dana ya da koyun eti parçalarıdır (Roux, 1989: 26).

Türk boyları, Orta Asya'dan Anadolu'ya göçleri sırasında oluşturmuş oldukları mutfak kültürlerini beraberlerinde taşırlar. Bu yolcuğun sonunda, coğrafyanın da etkisiyle tahıl, sebze, meyve ve baharatlarla zenginleşmiş bir Türk mutfağı karşımıza çıkar.

Selçuklu mutfak kültürü, eski Türk gelenekleriyle İslamiyet'e ait ögeleri birleştirir (Tezcan, 1997: 141). Selçuklu döneminde, konuklara ikram edilen yemekler arasında pilav çeşitleri, borani, yahni, kebap, keşkek, çorba, şerbet, tutmaç, tirit, bulamaç, ekmek ve sebze yemekleri sayllabilir (Demirgül, 2018: 112). X. asırdan itibaren Türk mutfağı dolaylı da olsa Bizans mutfağından etkilenir. Sütten üretilen peynir çeşitleri ve sunuma verilen önem, bu etkinin belirgin örnekleridir (Rice, 1989: 12).

Anadolu Selçuklu Devleti ve siyasi birliğinin bozulmasının ardından bă̆ımsızlıklarını ilan eden Türk beyliklerinin mutfak kültüründe sadelik esastır. Bununla beraber ziraat ve tarımla ilgilendikleri bilinen Anadolu Selçuklularına ait mutfak kabulleri hakkında ayrıntılı bilgiye sahip değiliz (Şahin, 2008: 45).

Osmanlı mutfağı, kuruluş devrinde Selçuklu mutfağından etkilenir. Bu dönemde mutfak kültürü, köy (taşra) ve şehir olmak üzere iki bölümde sınıflandırılabilir. Bu iki mutfağı birleştirerek günümüz Türk mutfağının temelini oluşturan ise Osmanlı saray mutfağıdır (Aktaş vd., 2007: 25). Bu mutfak, ilk defa Fatih Sultan Mehmet devrinde, Matbah-ı Âmire Emaneti adıyla kurulur. Bu dönemde, sabah ve akşam yemeği olmak üzere iki öğün yemek yenildiği bilinmektedir. Sarayın doğal konuklarına çıkarılan yemekler arasında lahana çorbası, yoğurtlu ve ıspanaklı borani, yoğurtlu pazı, yoğurtlu tutmaç, baş ve paça, yumurtalı lapa, pekmezli yoğurt tatlısı ve baklava sayılabilir. Vakitsiz gelen konuklara imaretlerde çıan standart bir mönüde ise pilav, yahni ve ekmek bulunur (Yiğit vd., 2016: 15-16). Osmanlı'da, tuzsuz tereyağında pişirilen kuzu, koyun, tavuk ya da balık etiyle hazırlanan kebaplar, yahni, külbastı, kızartma ve köftelerin yanı sıra pirinç pilavı çeşitleri, baklagil yemekleriyle çorba çeşitleri sofranın vazgeçilmez 
ögeleridir (Solmaz vd., 2018: 115-116). Fatih Sultan Mehmet devrinde başlayan Osmanlı mutfağının zenginliği diğer dönemlerde de devam eder. XV. asırda az sayıda olan yemek çeşitleri XVI. asırda artar. XVII. ve XVIII. asırlarda Osmanlı mutfağı görkemli dönemini yaşamaya devam eder. XIX. asırdan itibaren devletin girdiği ekonomik süreç Osmanlı saray mutfağını da etkiler (Güler, 2010: 25). Osmanlı'nın son döneminde, öğle ve akşam yemeklerinde et veya tavuktan başka börek, tatlı, birkaç çeşit sebze yemeğiyle pilavın bulunduğu bilinir (Saz, 1974: 54). XIX. asırda, Osmanlı İmparatorluğu'nun fakirleşme sürecine girmesi Türk mutfak kültürünü de etkiler.

Pilav, Osmanlı saray mutfağında sıklıkla tüketilen yemeklerdendir. Osmanlı mutfağına ait en eski pilav tarifleri, Şirvanî’nin kitabında bulunur ve II. Murat dönemine aittir. Şirvanî’ye göre muzaferiyye pilavı; tavuk, badem, safran ve şekerle; dane-i kabunî pilavı ise nohut ve etle yapılır. Fatih Sultan Mehmet'in sadrazamı Mahmut Paşa'nın ziyafetlerinde altın nohutlu pilav sunulduğu bilinir. Pirinç, XVI. asırdan itibaren Osmanlı mutfağında kendisine yer bulur (Demirgül, 2018: 116). XVI. asırda, Osmanlı saray mutfağında çalışan ve pilavcılar olarak bilinen bir aşçı grubu vardır. (Közleme, 2012: 133). XVI. ve XVII. asır ziyafetlerinde; yeşil dane, kızıl dane, sarı dane olarak sunulan pilavlarda renklendirme amacıyla safran, ıspanak ve nar suyu kullanılır. XVI. asırda; etli, biberli, kırmızı kuru üzümlü, helileli, lahanalı, meyveli ve sarımsaklı pilavlar yapılır. Sade pilavların üzerine kızartılmış badem ya da kuş üzümü konur. Kaymaklı peynirli pilava şeker karıştırılarak tatlı yapılır. Pilav yemeğin sonunda gelir. En eski tariflere göre pirinç, diğer malzemelerle pişirilir. Ancak XVIII. asra ait tariflerde, önce pirincin su veya et suyuyla haşlandığı kayıtlıdır. Priscilla Mary Işın’ın tespitlerine göre Acem, adi, balık, baş, biberli, böğrülce, düğün, hünkârî, güveç, iç, kabunî, kıymalı, köse, kükü, Medine, Mevlevi, midye, molozlu, muzaferiyye, sebzeli, susuz, sütlü, şehriye, tarak, temcit, yağll, yağsız, yoğurtlu, yufka ve zerde gibi isimlerle anılan pilav çeşitleri Osmanlı mutfağında pişirilir (Işın, 2017: 313-315).

Pilav, aynı zamanda Türk sosyal hayatında da önemli bir yiyecektir. Halk sofralarının vazgeçilmez ögeleri arasında yer alan pilavin Anadolu'da yeni doğan bebeklere ziyarete gelenlere ikram edildiği bilinir (Halıcl, 1997: 65).

Klâsik Türk edebiyatında, şairlerin kebap, mücver, dolma ve bakla gibi yemekleri şiirlerinde anlatı ögesi olarak kullandıkları görülür. Tarihsel süreçte Türk mutfağının daimi ögelerinden olan pilav da sosyal hayatın bir yansıması olarak şiirde anlatı ögesi olarak kullanılır. XVI. asır şairlerinden Ravzînin kaleme almış olduğu pilav kasidesi bu durumun ilgi çekici örneklerindendir (Aydemir, 2009: 150-151). Bu çalışmamızda, Ravzînin pilav konulu manzumesini Türk mutfak kültürünün verdiği bilgilerle incelemeye çalışacă̆ız.

\section{2. İnceleme}

Çalışmamızın bu bölümünde, öncelikle Ravzînnin tarihî kişiliği ile ilgili özet bilgiler vereceğiz. Daha sonra şairin pilav kasidesini şekil ve muhteva özellikleri açısından incelemeye çalışacağız.

\section{1. Ravzî’nin tarihî kişiliği}

Ravzî, günümüzde Balıkesir il sınırları içerisinde yer alan Edincik'tendir. Doğum tarihi belli olmayan şairin XVI. asrın ilk çeyreğinde doğduğu tahmin edilmektedir. Kanuni Sultan Süleyman, II. Selim, III. Murat ve III. Mehmet dönemlerini idrak eden Ravzî, aslı sipahi ve bey olan bir aileye mensuptur. Aldığı eğitimin derecesi bilinmemekle beraber, Arapça ve Farsça bildiği şiirlerinden anlaşılmaktadır. İstanbul, 
Bursa, Mihaliç, Gelibolu, Erdek, Dukakin, İştib ve Üsküp’te bulunan şairin ölüm tarihi bilinmemektedir (Aydemir, 2009: 12-25).

\section{2. Şekil incelemesi}

Ravzînnin pilav kasidesini öncelikle nazım şekli, vezin ve kafiye-redif özellikleri açısından değerlendirmeye çalışacağız.

\section{2. 1. Nazım şekli}

Ravzînin pilav övgüsünde kaleme aldığı manzumesi, kaside nazım şeklinin özelliklerini gösterir. Nazım şekli olarak kaside; ilk beyti kendi içerisinde, diğer beyitlerinin ikinci mısrası ise ilk beyitle kafiyeli olarak yazllan şiirlerdir. Övgünün esas olduğu kasideler, gelenek içerisinde çok çeşitli amaçlarla kaleme alınırlar (Saraç, 2007: 26). Kasideler, kendilerine özgü kompozisyon bütünlüğüne sahiptir. Giriş bölümü nesîb ya da teşbîb olarak adlandırılır. Bu bölümde şair, övgüye geçmeden önce aşktan bahseder ya da bir betimlemede bulunur. Daha sonra giriş bölümüyle övgüyü birleştiren ve okuyucuya övgünün başlayacağını haber veren girizgâh bölümü gelir. Medhiye adı verilen kasidenin üçüncü bölümünde şair, kasideyi sunacağı kişiyi çeşitli özelliklerini anlatarak över. Medhiye bölümünün ardından şairler, tegazzül adı verilen bölümde okuyucunun şiire olan ilgisini canlı tutma amacıyla gazel tarzında bir şiir söyleyebilirler. Tegazzül bölümünün ardından şairin şiirini ve şairlik gücünü övdüğü fahriye bölümü gelir. Kasidenin son bölümü ise dua adını alır (Dilçin, 2000, s. 125-152).

Ravzînin incelediğimiz kasidesi, form açısından değerlendirildiğinde klâsik kaside planına uymaz. 21 beyit uzunluğundaki kaside, doğrudan pilavın övgüsüyle başlar ve söz konusu övgü 12. beyte kadar sürer. Bu beyitlerde; şairin pilav yemediği için özlem duygusu içerisinde olduğu görülür. Manzumenin 13.-15. beyitlerindeki ifadelerden ise şairin Sultan III. Murat'ın düzenlemiş olduğu bir ziyafette özlediği pilav yemeğine kavuştuğu anlaşılır. 15. beyit, dolaylı olarak sultanın övgüsünü içerir. Kasidenin 16.-21. beyitleri ise anlam yönüyle 1.-12. beyitlere benzer.

\section{2. 2. Vezin}

İncelememize esas olan Ravzînin pilav kasidesi, aruzun fâ'ilâtün/ fâ’ilâtün/ fâ’ilâtün/ fâ'ilün kalıbıyla yazılmıştır. Kasidede, ciddi aruz kusurlarına rastlanmaz. Klâsik Türk edebiyatında şairlerin çeşitli nedenlerle başvurdukları imale, ulama ve med bu manzumede ahenk ögesi olarak karşımıza çıkar (b. 2).

\section{2. 3. Kafiye-redif}

Ravzî̀nin incelediğimiz kasidesinde kullandığı kafiye ve redif şu şekildedir:

\begin{tabular}{lll}
\hline & Kafiye & Redif \\
\hline $\mathbf{K}$ & -Ân & -Muz pilâv \\
\hline
\end{tabular}

Şekil 1: Kafiye ve Redif Tablosu

Şekil 1'den de anlaşılacağı üzere şairin kafiye olarak kullandığı hecenin manzumeye ahenk kattığı, redif olarak seçtiği hece ve kelimenin ise manzumeyi belli bir anlam çerçevesinde topladığı görülür. 


\section{3. Muhteva incelemesi}

Bu başlık altında Ravzînin kasidesi, muhteva özellikleri açısından incelenecektir.

\section{3. 1. Gida olarak pilav}

Ravzî, pilavı can ve ruhun gıdası olarak niteler (b. 1). Açlı̆̆ının çaresi olan bu gıdaya ulaşamamaktadır. Can, insan ve hayvanda bedenle beraber yaşamayı sağlayan ögedir (Sami, 2010: 164). Yaşamın devamlılı̆̆ dolayısıyla vücudun sağlığı için beslenmemiz gerekir. İslami açıdan ruhun beslenmesi ve yaşamaya devam edebilmesi için gerekenler din ve imandır. Ravzî kasidesinde, ruhun gıdası olarak pilavı kabul ederek onu bedensel varlığın devamını sağlayan bir maddi gıda değil daha çok din ve iman gibi ruhun devamlılı̆̆ını sağlayan manevi bir gıda olarak değerlendirir.

Şair, diğer bir beytinde pilavin kokusuna yoğunlaşır (b. 4). Evinde, zaman zaman yediğinde hayran olduğunu söyler. Böylelikle çok sevdiği bu yemeğe, ulaşamadığını dolaylı olarak ifade eder. Şair, pilava olan özlemini dile getirirken "burnunda tütmek" deyimini seçer. Bu deyim, herhangi bir şeye duyulan aşırı özlemi ifade ederken kullanılır (Akyalçın, 2012: 169). Şair, böylece Türkçenin ifade kalıplarına yönelir.

Hakikat, görünenin ardında bulunan gizli anlama aşina olmak, Tanrı'nın tecellilerini temaşa etmektir (Demirci, 1997: 178-179). Cahil; bilgisiz, habersiz, okuyarak bilgisini ilerletmemiş kimsedir (Ayverdi, 2016: 179). Ravzî̀ye göre pilav, hakikat ehlinin canına can katar. Bu nedenle cahillerin ağzına layık değildir (b. 7).

Ravzî, yaratılışını at, yemek sofrasını ise meydan olarak hayal eder ve yaratılış atının sofra meydanına gelip pilavı gördügüunde onun her tanesini yiyebilmek için ağzındaki dişlerin sabırsızlandığını söyler (b. 19). Şair, içinde bulunduğu özlem duygusunu ve sabırsızlık hâlini anlatırken iyi bir pilavın tane tane pişirilmesi kabulüne de telmihte bulunur.

Hz. Peygamber'in cennet meyvesi olarak nitelendirdiği, müminin özelliklerini taşıdığını ifade ettiği hurma ağacı, Arabistan'ın başlıca bitkisidir. Bu ağaç, Kur'ân-ı Kerim’de yirmi üç kez ismen anılır (Bozkurt, 1998: XVIII/ 391-393). Şair, pilavı hurma ağacına benzetir. Devrin sultanı III. Murat'ın Sultanahmet'teki Hipodrom alanıyla Sultanahmet Camisi arasından geçerek Ayasofya Meydanı'na ilerleyen cadde olan Atmeydanı'nda kurduğu bir ziyafete giden şair, önce sofrayı seyreder (b. 13). Sofrada uzun zamandır özlem duyduğu pilavın olduğunu görür. Onu şekli itibariyle Ayasofya'nın kubbesine benzetir. Heyecanlanır ve pilavın dini imanı olduğunu söyler (b. 14). Sultan III. Murat'ın kendisine pilav sunmasından dolayı Tanrı'ya şükreder (b. 15).

\section{3. 2. Sevgili olarak pilav}

Ravzî’nin incelememize esas olan kasidesinde pilavı kişileştirdiği, onu sevgili olarak hayal ettiği görülür. Bu durumda âşık konumunda bulunan Ravzî, sevgilinin özlemini çeker. O, âşık olarak sevgiliye kavuşma isteğindedir. Bu isteğinin gerçekleşmemesinden dolayı yüzünün renginin sararmasıyla zerde tatlısının rengi arasında benzerlik ilgisi kurar. Zerde, pirinçten yapılan bir tatlıdır. Safran veya zerdeçal, gülsuyu içerisinde bekletilir. Hafif ateşte yumuşayıncaya kadar pişirilen pirince bir miktar şeker ilave edilir ve kaynatılır. Daha sonra safranlı gülsuyu ilave edilir ve kaynatılmaya devam edilir. Ilık suyla ezilmiş nişastanın eklenmesinin ardından beş dakika kadar daha kaynatılır. Soğumasının ardından üzerine tarçın serpilir. Üzüm, nar ve fistıkla süslenerek servis edilir (Halıcı, 2009: 277). Zerdeye kendi özel 
rengini veren safran ya da zerdeçaldır. Ravzî, sevgilinin ayrllı̆̆ının verdiği hararetle yüzünün safran ya da zerdeçal katılarak kaynatılan zerde gibi sarardığını söyler (b. 6). Şair, bu hâlde pilava seslenerek damarlarında bir damla kanın kalmadığını, kuruduğunu ifade eder.

Şaire göre pilav, güler yüzlü bir gül yaprağı; güzel kokular saçan güzel bir sevgili gibidir (b. 9). Âşık, onu gördüğünde mutlu olur, sevinci artar (b. 10). Ayrılığında ise feryatla yakasını parça parça eder (b. 21). Ancak o sevgili, her zaman kendisini âşıklara göstermez. Bu durumda âşı, sevgiliye benzeyen pilavın bir kere meclise gelmesini, orada toplanmış olan dostların onu meclisin orta yerine almasını diler (b. 11). Ravzî, böylece bir toplantı meclisi hayali kurar. Pilavın geldiği sofrayı, gökyüzü sofrası olarak nitelendirir. Böylelikle pilavı rengi yönüyle de aya teşbih eder (b. 12).

\section{3. 3. Hükümdar olarak pilav}

Ravzîye göre pilav, hükümdardır. Bu noktada Ravzî, gelenekteki benzer örneklerinde görüldüğü üzere hükümdara aç, yiyeceksiz, muhtaç ve zelil bir hâlde olduğunu söyleyerek kendisini açlık askerinin ayakları altına itmemesi için yalvarır (b. 2). Ravzî, bu ifadeleriyle en eski Türk geleneğindeki kabullere telmihte bulunur. Orhun Abideleri’nde de ifadesini bulan Türklüğün kut anlayışına göre hükümdar, aç halkı doyurmalı, çıplak halkı giydirmelidir (Tekin, 2003: 47).

Şaire göre pilav, ulaşılmaz bir sultana benzemektedir. Bu noktada Ravzî, pilavı gönül sultanı olarak nitelendirir (b. 2). Şairin ifadelerine göre emsalleri ve akranları onu görmemiştir. Herkes onu görmeyi istemektedir (b. 5).

\section{3. 4. Gizli hazine olarak pilav}

Pilav, Ravzînnin gizli hazinesidir. Şair, pilavı göremez olduğunu söyler ve onun Kârûn'un hazinesi gibi yerin dibine girip girmediğini sorar (b. 3). Kârûn, Hz. Musa'nın akrabalarındandır. Mü'min suresinin 23.-24. ayetlerinde ismi, Firavun ve Hâmân ile birlikte anılır (Karaman vd., 2006: 468). Kârûn, toprağı altın hâline getirmeyi öğrenir ve böylece çok zengin olur. Hz. Musa'nın istemiş olduğu zekâtı vermediği için servetiyle beraber yere batar. Edebiyatımızda zenginliğin timsalidir (Onay, 2009: 277).

\section{3. 5. Yakut-inci-mercan gibi değerli taşlara benzemesi yönüyle pilav}

Ravzîye göre pilav, olgun kimselerin lokması, Bedahşan yakutu gibidir. Bedahşan, Afgan Türkistanı olarak da bilinir. Kuzeyinde Amuderya, güneyinde Hindukuş dağları, doğusunda Doğu Türkistan, batısında ise Kunduz ırmağıyla çevrilidir (Saray, 1992: V/ 291). Klasik Türk edebiyatında, kıymetli madenlerden la lin en meşhur cinsinin bu şehirde çıkması yönüyle anılır (Uzun, 1992: 292). Şair, pilavın rengiyle Bedahşan yakutu arasında ilgi kurarak Osmanlı mutfağında renk vermesi amacıyla pilava nar suyu karıştırılması âdetine telmihte bulunur (b. 16).

Şairin pilavı benzettiği diğer değerli taşlar ise mercan ve incidir. Bu açıdan pilavın her tanesi tespih yapımında da kullanılan inci ve mercan gibidir. Böylece şair, Osmanlı'da tespih yapımıyla ilgili kabullere de telmihte bulunur (b. 20).

\section{3. 6. Kible olarak pilav}

Ravzî, incelememize esas olan kasidesinde pilavı canının kıblesi olarak nitelendirir. Bu noktada, Kâbe gibi bazen neden siyah giyindiğini sorar (b. 17). Pilavın zaman zaman Kâbe gibi siyah giyinmesi ifadesi 
ise kapalı ve yoruma açıktır. Türk mutfağında, pilava pişirilirken renklendirmek amacıyla çeşitli özlerin karıştırıldığı bilinmektedir. Koyu bir renge sahip olması yönüyle bulgur pilavı da Osmanlı mutfağında XVI. asra kadar yaygındır.

\section{3. 7. Hz. Ali’nin neslinden gelenlere benzemesi yönüyle pilav}

Ravzî, kasidesindeki diğer bir beyitte renklendirmek amacıyla pilava ıspanak suyu karıştırılması âdetine telmihte bulunur (b. 18). Bu açıdan pirinç tanelerini, Hz. Ali'nin soyundan olup meclise gelenler olarak nitelendirir.

\section{Sonuç}

Pilav, varlığı tarihin en eski devirlerine kadar uzanan Türk mutfak geleneğinin popülaritesini her dönemde korumuş yemeklerindendir. Osmanlı saray mutfağında, çeşitli özlerle renklendirilen ve farklı besin maddeleriyle zenginleştirilen pilav, şiirde de sosyal hayatın bir yansıması olarak kendisine yer bulur. XVI. asır şairlerinden Ravzî’nin kaleme almış olduğu pilav övgüsündeki kaside bu durumun ilginç bir örneğidir. Ravzî, pilavı öncelikle bir gıda maddesi olarak ele alır. Ona duyduğu özlemi, mübalağalı bir üslupla dile getirir. Ravzî için pilav aynı zamanda sevgili, hükümdar, gizli bir hazine ve kıbledir. Şairin bir beyitte pilav ile Hz. Ali’nin neslinden gelenler arasında ilgi kurması ise dikkat çekicidir. Sosyal hayattan aldığı telmih ögelerini, din-tasavvuf, mitoloji ve coğrafya bilgisiyle birleştirerek şairane bir üslupla sunan şairin bu şiiri, orijinal ifadeleriyle Türk mutfak kültürünün edebiyata yansımasını çeşitli yönlerden örneklendirir.

\section{Kaynakça}

Aktaş, A. \& Özdemir, B. (2007). Otel işletmelerinde mutfak Yönetimi (2. Baskı). Ankara: Detay.

Akyalçın, N. (2012). Türkçenin anlamsal zenginlikleri deyimlerimiz. Ankara: Eğiten Kitap.

Argıllı, E. (2005). Elif in mutfağından ağzınıza layık 400 tarif. İstanbul: Omega.

Aydemir, Y. (2009). Ravzî divanı. Ankara: Birleşik.

Ayverdi, İ. (2016). Misalli büyük Türkçe sözlük (3. Baskı). İstanbul: Kubbealtı İktisadî İşletmesi.

Baysal, A. (1993). Beslenme kültürümüz. Ankara: KTB.

Bozkurt, N. (1998). Hurma. Diyanet vakfı İslam ansiklopedisi. C. 18. İstanbul: Diyanet Vakfi, 391-393.

Ciğerim, N. (2001). Batı ve Türk mutfağının gelişimi, etkileşimi ve yiyecek-içecek hizmetlerinde Türk mutfağının yerine bir bakış. Türk mutfak kültürü üzerine araştırmalar. Ankara: Türk Halk Kültürünü Araştırma ve Tanıtma Vakfı, 49-61.

Demirci, M. (1997). Hakikat. Diyanet vakfi İslam ansiklopedisi. C. 15. İstanbul: Diyanet Vakfı.

Demirgül, F. (2018). Çadırdan saraya Türk mutfağı. Uluslararası Türk dünyası turizm araştırmaları dergisi, $3,105-125$.

Dilçin, C. (2000). Örneklerle Türk şiir bilgisi (6. Baskı). Ankara: TDK.

Güler, S. (2010). Türk mutfak kültürü ve yeme içme alışkanlıkları. Dumlupınar üniversitesi sosyal bilimler enstitüsü dergisi, 26, 24-30.

Halıcı, N. (1997). Anadolu bayramlarında beyaz renkler. Türk mutfak kültürü üzerine araştırmalar. Ankara: Türk Halk Kültürünü Araştırma ve Tanıtma Vakfı, 65-67.

Halıcı, N. (2009).Türk mutfağı (2. Baskı). İstanbul: Oğlak.

Işın, P. M. (2017). Osmanlı mutfak sözlüğü (2. Baskı). İstanbul: Kitap. 
Karaman, H. \& Özbek, A. \& Dönmez, İ. K. \& Çağrıcı, M. \&Gümüş S. \& Turgut, A. (2006). Kur’ân-ı Kerîm ve açıklamalı meali. Ankara: Diyanet Vakfı.

Közleme, O. (2012). Türk mutfak kültürü ve din. PYayımlanmamış doktora tezi. İstanbul: Marmara Üniversitesi Sosyal Bilimler Enstitüsü.

Onay, A. T. (2009). Açıklamalı divan şiiri sözlüğü (eski Türk edebiyatında mazmunlar ve izahı). Haz.: Cemal Kurnaz. İstanbul: $\mathrm{H}$.

Ögel, B. (1991). Türk kültür tarihine giriş, C. 4, Ankara: KTB.

Rice, T. T. (1989). Bizans'ta günlük yaşam (Bizans'ın mücevheri Konstantinapolis). Çev.: Bilgi Altınok. İstanbul: Göçebe.

Roux, J. (1989). Türklerin tarihi. Çev.: Galip Üstün. İstanbul: Milliyet.

Sami Ş. (2010). Kâmûs-ı Türkî. Haz.: Paşa Yavuzarslan. Ankara: TDK.

Saraç M. A. Y. (2007). Klâsik edebiyat bilgisi (biçim-ölçü-kafiye). İstanbul: 3 F.

Saray, M. (1992). Bedahşan. Diyanet vakfı İslam ansiklopedisi, C. 5. İstanbul: Diyanet Vakfı, 291-292.

Saz, L. (1974). Harem’in iç yüzü. Düz.: Sadi Borak. İstanbul: Milliyet.

Solmaz Y. \& Altıner D. D. (2018). Türk mutfak kültürü ve beslenme alışkanlıkları üzerine bir değerlendirme. Safran Kültür ve Turizm Araştırmaları Dergisi, 3, 108-124.

Şahin, H. (2008). Türkiye Selçuklu ve Beylikler dönemi mutfağı. Türk mutfağı. Ankara: KTB.

Tekin, T. (2003). Orhon yazıtları (Kül Tigin, Bilge Kağan, Tunyukuk). İstanbul: Yıldız Dil ve Edebiyat.

Tezcan, M. (1997). Yemek kültürü üzerine dinsel etkiler. Türk mutfak kültürü üzerine araştırmalar. Ankara: Türk Halk Kültürünü Araştırma ve Tanıtma Vakfı, 139-146.

Uzun, M. (1992). Bedahşan: Edebiyat, Diyanet vakfı İslam ansiklopedisi. C. 5. İstanbul: Diyanet Vakfı, 292-293.

Yiğit, Y. \& Ay, E. (2016). Osmanlı mutfak kültürü. 3rd Intertanional congress on social sciences, China to Adriatic, 8-22.

Ek:

\section{Metin}

Kanda gitdün ey gıdâ-yı rûhum ey cânum pilâv

Haste-i cứum gel ey dermân-ı cevânum pilâv

Kaldum aç u zâr u muhtâc u zebûn u bî-nevâ

Pây-mâl-i leşker-i cư‘ itme sultânum pilâv

Mâl-ı Kârûn gibi nâ-geh yere mi geçdün 'aceb

Görmez oldum ben seni ey genc-i pinhânum pilâv

Cân dimâgın âh kim bûy-ı dil-âvîzün tutar

Hânesinde gâh geh yidükçe hayrânum pilâv

Ârzû eyler seni zîrâ gönül sultânıdır

Görmedi gerçi benüm emsâl ü akrânum pilâv

Benzümi zerdeye dönderdi teb-i hecrüy senüy

Kurıdı kalmadı tende katrece kânum pilâv

Degme nâ-dân agzina lâyık degülsin hak budur

Ey gıdâ-yı cân-fezâ-yı ehl-i irfânum pilâv 
Dâr-ı Çînîler ekilmiş hûb kab-ı nevlere

Mâ'ilin gâyetde ey şâh-ı Horasân'um pilâv

Gayrı yimekler senüy yanuyda gülmez yüzlüdür

Şûh-ı ra'nâsın sen ey gül-berg-i handânum pilâv

Yüzüni gün gibi görsem her sabâh u şâmda

Cân katarduy cânuma 'âlemde cânânum pilâv

Lutf u ihsân eyleyüp bir kerre gelsen meclise

Alsa ortaya seni mecmû‘'-1 yârânum pilâv

Şol mücellâ sâhanuy içinde sipihr süfrede

Hâle içre mâhsın ey mihr-i rahşânum pilâv

Sûr-ı şâhı seyre vardum bir gün Atmeydânı'na

Salını salını ey nahl-i hırâmânum pilâv

Ayasofya kubbesi sandum görüp nâ-geh seni

Yüregüm kopdı hemân ey dînüm îmânum pilâv

Hakk'a yüz bì şükr ü minnet kim bana kıldı 'atâ

Şeh Murâd bin Selîm bin Süleymân'um pilâv

Gâh olur kim kırmızı renge girersin gül gibi

Ey ekâbir lokması la'l-i Bedahşân'um pilâv

Kâ'be gibi geh siyeh-pûş oldugun bilsem nedür

Ey safâ-yı hâtırum ey kıble-i cânum pilâv

Geh yeşil destâr ile teşrîf idersin meclisi

Bezme geldi sanki Âl-i Şîr-i Yezdânum pilâv

Esb-i tab'um süfre meydânında görse her kaçan

Gem gever her dâneye agzımda dendânum pilâv

Dâne-i tesbîhe benzetdüm senüy her dâneni

Dilde zikrim sevdügüm yâkût u mercânum pilâv

Niçe feryâd itmeyem senden cüdâ Ravzî-sıfat

Dest-i hecrün çâk ider dâ’im girîbânum pilâv 